\title{
Indeterminação; o "Admirável"; a Crescente Comunicabilidade*
}

\section{RESUMO}

A partir de vários trabalhos recentes sobre a atual configuração do campo da Comunicação no país, observa-se uma ênfase recorrente em fenômenos caracterizados como "incertos", da esfera do "sensível", "intuitivos", "subjetivos", marcados pela "diversidade", "despercebidos" e "instáveis". Daí, e a partir da compreensão de que os processos comunicativos consistem, eminentemente, de representações sígnicas, procuraremos apresentar a idéia de que o conceito de "esteticamente admirável", de Charles S. Peirce, pode ser útil para entendermos esta convergência de posturas epistemológicas.

\section{PALAVRAS-CHAVE}

comunicação

epistemologia

semiótica

\section{ABSTRACT}

Recent papers about the current shape of the Communication field in Brazil show a stress on phenomena characterized as "uncertain"; from the sphere of "sensible"; "intuitive"; "subjective"; marked by "diversity"; "unperceived" and "unstable" According to this and considering that all communication processes involves signic representations, we present the idea that the "aesthetic admirable" concept from Charles S. Peirce can be useful for the understanding of this epistemological convergence..

\section{KEY WORDS}

communication

epistemology

semiotics
Este trabalho busca estabelecer articulações entre posturas diversas frente ao problema da configuração do campo da Comunicação no País, a partir de convergências observadas em trabalhos apresentados no encontro de 2007 do Grupo de Trabalho Epistemologia da Comunicação da Associação dos Programas de Pós-Graduação em Comunicação - Compós. Embora sustentados em vertentes de análise bastante diferentes, nove dos dez trabalhos selecionados têm, curiosamente, em comum suas ênfases relacionadas a fenômenos caracterizados como "incertos", da esfera do "sensível", "intuitivos", "subjetivos", marcados pela "diversidade", "despercebidos" e "instáveis".

Daí, e a partir da compreensão de que os processos comunicativos consistem, eminentemente, de representações sígnicas, procuraremos apresentar a idéia de que a categoria semiótica da Primeiridade e o conceito a ela associado de "esteticamente admirável", de Charles S. Peirce, podem ser úteis para entendermos esta convergência de posturas epistemológicas.

\section{A percepção da indeterminação}

Na comunicação apresentada por Melena Contrera no Compós 2007, intitulada "Em Meio ao Desencanto", a autora critica a influência dos paradigmas "mecanicistas e cartesianos" sobre os estudos da Comunicação no atual contexto de "desencanto". Em oposição a isto, defende, em seu parágrafo final:

Só uma espécie de reencantamento, por meio da consideração da consciência participativa, da empatia e dos vínculos no processo de comunicação, será capaz de trazer vida a uma teoria da comunicação, aproximando-a (ainda que incomodamente) do terreno incerto e incontrolável da alma humana (Contrera, 2007, p.11).

Assim, a autora trabalha com o conceito de consciência participativa, ligado às idéias de "comunhão" e até mesmo de "participação mística", como contraponto ao "espírito funcional" que teria impregnado os diversos campos do saber, entre eles o da Comunicação. Portanto, ao propor um movimento rumo ao terreno do "incerto" e do "incontrolável", sustenta que a solução para o problema da definição do campo seria algo que se dirigiria à esfera da indeterminação.

Já no trabalho "O Acontecimento Comunicacional", Tarcyane Santos enfatiza o "caos epistemológico" que teria dominado a área da Comunicação face ao "impacto das novas tecnologias". Segundo a autora, "a comunicação, o tornar comum, não é a busca de um sentido único ou a homogeneização dos seres" e pode-
Francisco José Paoliello Pimenta

Professor do Programa de Pós Graduação em Comunicação da UFJF/MG/BR paoliello@acessa.com 
ria ser percebida através do acontecimento, ou seja, de "algo extralingüístico que permite a compreensão do sentido" (Santos, 2007, p.11). Com base em MerleauPonty, a argumentação prossegue afirmando que "a comunicação pressupõe a nossa abertura às sensações" (Idem, Ibidem) para, ao final, defender que "sempre haverá na comunicação uma sombra, zona nebulosa, que esconde parte do que se deseja comunicar" (Idem, p.12). A autora afirma, ainda, que a "presença e força do não-visível permitem que vejamos os sons e escutemos as cores" (Idem,p.13-14). Neste caso, a crítica ao homogêneo, ao lingüístico, vem por meio da defesa de uma "abertura às sensações" em direção a uma "zona nebulosa" e "não-visível", isto é, reaparece a ênfase na indeterminação sígnica.

\section{Ao compreendermos a} diversidade como matriz epistêmica, 0 "contexto" nos forneceria a instrumentação teórica para lidarmos tanto com "o dentro" como com "o fora", ou seja, com as conexóes imprevisíveis dela decorrentes, atuantes por meio da "mente da cultura".

Regina Rossetti, em "A Linguagem como Mediação da Intuição", argumenta que só é possível enfrentar o caráter mutável da comunicação por meio da intuição. Entretanto, como a intuição não possuiria expressão, linguagem, e não seria comunicável, haveria a necessidade de valorização das imagens e das metáforas. Com base em Bergson, a autora afirma que a intuição, ao contrário do caráter exterior da inteligência, "adentra o objeto, coincide com ele, segue os contornos de seu movimento interior, e, assim, atinge o absoluto, o conhecimento essencial do objeto" (Rosseti, 2007, p.4). Daí, face à impossibilidade do conceito traduzir o intuitivo, que lhe seria anterior, chega-se à defesa das imagens e metáforas:

Um saber mediado precisa transcender os conceitos rígidos para chegar à intuição movente, e libertar-se de conceitos pré-fabricados, para criar 'representações flexíveis, móveis, quase fluidas, sempre prontas a se moldarem sobre as formas fugitivas da intuição' (Bergson, 1984, p.19), e assim tentar comunicar a essência dos fenômenos. É preciso inspirar-se na arte que se expressa mais por imagens e metáforas e que pode nos dar o sentido de uma linguagem capaz de sugerir o ser mais do que dizê-lo (Brincourt, 1955, p.43). Essa inspiração aponta um dos motivos da convergência entre comunicação e artes na cultura contemporânea como superação da tradicional fronteira entre ciência e arte (Santaella, 2005, p.13 e p.68).

Portanto, mais uma vez, a proposta de um dos trabalhos do grupo enfatiza aquilo que é mutável, intuitivo e indeterminado.

Da mesma forma, o artigo de Paulo Masella, "Comunicação: entre o Espaço Visível do Meio Técnico e o Invisível do Acontecimento", destaca, já a partir do título, e a exemplo de Tarcyane Santos, a necessidade de ver o fenômeno comunicacional como "acontecimento", algo que muitas vezes seria colocado à margem, na esfera do "invisível". No texto, ao opor o acontecimento à técnica, o autor o insere numa "matriz espacial", na medida em que sua ocorrência dependeria de um espaço comum de pertencimento, numa relação entre corpos e, também, de subjetividades. Diz Masella:

Se há uma política nas relações entre os meios técnicos e a sociedade, há igualmente uma política que permeia a comunicação entre os corpos que não é mediada só pela palavra, pela escrita ou pelo discurso, mas também pelo silêncio, pelo desejo e pelo indizível; por um espaço de subjetividade que os meios técnicos colocam sistematicamente à margem, em uma zona de invisibilidade (Masella, 2007, p.4).

A partir deste pensamento, também sustentado em Merleau-Ponty, Masella defende que a própria epistemologia tenha uma matriz espacial, o que permitiria enxergar os meios de comunicação em seu papel limitado de geradores de um discurso técnico de controle de distâncias, por meio de imagens, sons e textos, que excluiriam não só as relações entre os corpos em seu "espaço contínuo de intersubjetividade" (Idem, p.10), mas também sua "virtualidade" (Idem, p.12). Portanto, o autor também reivindica a atenção para um espaço da comunicação marcado pelo silêncio, pelo indizível e pela virtualidade, algo de uma esfera próxima à das ênfases registradas acima.

No artigo de Irene Machado, "Em Contexto, Fora de Contexto: experiências sistêmicas nos estudos da comunicação como mente da cultura", o destaque é para o conceito de "contexto", com base nas idéias de Lotman e Bateson. O conceito serviria como saída para uma compreensão "subversiva" e "ecológica" das diversidades decorrentes das interações comunicativas desencadeadas pelos "signos informáticos". Segundo 
a argumentação, ao compreendermos a diversidade como matriz epistêmica, o "contexto" nos forneceria a instrumentação teórica para lidarmos tanto com "o dentro" como com "o fora", ou seja, com as conexões imprevisíveis dela decorrentes, atuantes por meio da "mente da cultura". Diz a autora:

Em contexto, interação pode ser convergência; isto não quer dizer eliminação de confrontos. Uma coisa é afirmar a interação na diversidade que se encaminha para a convergência de ações. Outra bem diferente é alcançar o conflito como base da interação que mantém a divergência, abrindo caminho para o surgimento de hibridismos, paradoxos, relações, transmutações. Tal instabilidade é a visão que projeta a ecologia como outra episteme, distinta das ciências naturais. (Machado, 2007, p. 4)

Como se pode ver também esta argumentação destaca como elemento crucial para a epistemologia da comunicação fenômenos da esfera da indeterminação sígnica, ou seja, a divergência e a instabilidade, vistas a partir de uma concepção que privilegia o que está "fora do contexto" e, portanto, dos significados gerados pela atual "mente da cultura".

José Luiz Braga, por sua vez, no texto “Comunicação, disciplina indiciária", chama a atenção para os indícios decorrentes de estudo de casos como saída para uma melhor definição do campo da Comunicação. Contudo, segundo o autor, estes indícios estão sujeitos a muitas possibilidades interpretativas, ao acidental, e daí, a partir de Carlo Ginzburg, sua principal referência, defende a busca de pormenores negligenciáveis para se chegar às pistas certas. Diz Braga:

Na psicanálise freudiana, a busca de elementos "despercebidos" (que surgem como emanação direta do inconsciente) é essencial para descobrir estruturas profundas da psique do indivíduo - enquanto os traços mais evidentes da personalidade, sendo conscientes, podem ser "trabalhados" intencionalmente para ajustar-se aos padrões culturais aceitos. Estes últimos indícios seriam pistas para outra questão - a do comportamento cultural expresso pelo indivíduo em sociedade - por exemplo, nas pesquisas de psicologia social. (Braga, 2007, p.9)

Mais à frente, o texto destaca a necessidade de um "trabalho de 'descoberta', ou 'invenção", que seria "inevitavelmente, um processo de risco" (Idem, p.12). Neste ponto, Braga faz uma referência ao conceito de abdução de Peirce, da esfera da Primeiridade, por meio de citação na qual aparece a idéia de que a hipótese seria originária deste âmbito frágil da descoberta. Portanto, mais uma vez, a indeterminação reaparece como instância central para a compreensão dos processos comunicacionais na contemporaneidade.

O trabalho de Vera França, "Contribuições de G.H. MEAD para Pensar a Comunicação", traz conceitos do interacionismo simbólico para fundamentar uma reflexão sobre a relevância da linguagem gestual como mecanismo de base para a dinâmica relacional e a configuração das interações no processo comunicativo. A exemplo dos vários autores citados acima, Vera França enfatiza um aspecto dos processos representativos avesso às formalizações, afastado de codificações já cristalizadas da linguagem verbal, ao conferir ao gestual uma posição chave para uma melhor compreensão da interação social que sustenta a comunicação. Diz a autora:

O estudo da comunicação compreende então o estudo de um ato que se desenvolve (dimensão prática) e da relação que aí toma forma (dimensão relacional) através de gestos significativos. Trata-se de recortar as intervenções concretas dos indivíduos implicados, isto é, os gestos, as atitudes, assim como as significações que as animam (dimensão simbólica, presença do sentido), buscando captar o movimento reflexivo que orienta a configuração do processo. (França, 2007, p.8)

Ao valorizar, assim, este código, o texto também busca enfatizar algo da esfera do indeterminado, uma vez que a comunicação gestual permite múltiplas interpretações em vista da fragilidade das conexões que estabelece entre signo e objeto.

Finalmente, o texto de Maria Immacolata Lopes, "Comunicação, Disciplinaridade e Pensamento Complexo", intenta descrever o processo histórico de constituição das Ciências Sociais, com ênfase em suas motivações políticas e no caráter arcaico da divisão em disciplinas. Segundo Immacolata, o novo contexto da sociedade global gera uma crise epistemológica que acaba por favorecer as abordagens transdisciplinares, o que pode ser um caminho interessante para o campo da Comunicação, caracterizado por sua "institucionalização débil". Com base no conceito de pensamento complexo de Morin, a seção final do texto tece um roteiro que parte da idéia de Prigogine de "fim das certezas" para concluir com a proposta de se pensar o problema epistemológico como saber "sem lugar", atópico, impossível de ser situado numa escala disciplinar. Diz a autora:

A tônica em que insisto vai para aquilo que é complexo, temporal, instável, e que corresponde a um movimento transdisciplinar que se afirma progressivamente. A crítica central recai sobre a artificialidade dos limites disciplinares construídos notadamente no século XIX, tanto entre os domínios das Ciências Exatas, das Ciências Sociais e das Humanidades, como entre as disciplinas dentro de cada domínio, 
limites esses que foram mantidos mais por tradições institucionais do que intelectuais. Os desafios trazidos pela compreensão de novos campos de estudo, como é a Comunicação, encaminham para a formação de novas sínteses disciplinares ou convergências disciplinares, isto é, de transdisciplinas ou pós-disciplinas. (Lopes, 2007, p.13)

É fácil verificar a similaridade desta argumentação com os destaques extraídos dos textos citados acima, na medida em que a própria autora qualifica o campo da Comunicação como algo "débil", num contexto incerto, de atopia, ao mesmo tempo em que aponta para uma saída da ordem do "instável".

Esta curiosa convergência também opera no trabalho de nossa autoria, intitulado "Semiótica, como teoria da representação, e o campo da Comunicação", no qual a esfera da indeterminação foi abordada em diferentes momentos. Em primeiro lugar, destacamos que, sob o ponto de vista da semiótica peirceana, tomada como teoria da representação sígnica, é possível incorporar a dispersão observada no campo da Comunicação como elemento constituinte dos fenômenos, em seu aspecto de mera possibilidade de ocorrência, característico da categoria da Primeiridade. Isto porque, segundo Peirce, a maioria das relações que ocorrem na natureza são fortuitas e irregulares (Peirce, 1931-58, CP 5.342):

Somos conduzidos, então, a isto: a conformidade à lei existe somente dentro de uma faixa limitada de eventos e mesmo aí ela não é perfeita, pois um elemento de pura espontaneidade ou originalidade sem lei se intromete, ou, pelo menos, parece se intrometer na lei em todos os lugares. Além disso, conformidade com a lei é um fato que exige explicação e desde que leis, em geral, não podem ser explicadas por nenhuma lei em particular, a explicação deve consistir em mostrar como a lei desenvolve-se a partir de puro acaso, irregularidade e indeterminação (Peirce, 1931$58, \mathrm{CP} 1.407)$.

A partir daí, argumentamos que muitos dos eventos que vêm gerando indeterminações no campo vieram da esfera da comunicação digital, ao articularem ao verbal, de forma cada vez mais rápida e crescente, imagens e sons. Ou seja, estes signos híbridos e complexos teriam, em si, a qualidade de incluir em seus processos a baixa definição, ampliando, assim, a representação de eventos por meio de uma riqueza maior de características, incluindo aspectos de indeterminação. E, finalmente, defendíamos que, pela perspectiva epistemológica de se considerar o campo da Comunicação como objeto, seria importante observar que ele compartilha este caráter de indeterminação, de Primeiridade, com os fenômenos que intenta pesquisar e representar quando o consideramos em seu papel de signo.

\section{A indeterminação como um Universal}

Tal conceito de Primeiridade, estreitamente vinculado à idéia de indeterminação, é uma das mais importantes e mal compreendidas contribuições teóricas de Peirce. Sua origem está na filiação do autor ao Realismo Escolástico e à sua defesa da "realidade dos Universais". A questão surge com Sócrates, quando este sustenta contra os sofistas que o verdadeiro objeto do conhecimento é o que existe de comum nos seres individuais de um grupo, propondo a existência de um Belo em si e por si, um Bem, e assim por diante. Platão também retira daî sua teoria das Idéias ou das Formas, imutáveis, eternas e incorpóreas, a partir das quais os objetos seriam criados e classificados pelo intelecto. Já para Aristóteles, Universais são substâncias num sentido derivado, pois existem somente como elementos comuns em particulares, os quais podem ser apreendidos pelos sentidos, com a ajuda da memória de experiências anteriores, e classificados pela ciência em espécies, aos quais já pertencem naturalmente. Portanto, Aristóteles é um Realista, pois defende a realidade dos Universais, mas moderado, pois, para ele, o universal e o particular dependem um do outro.

\section{Universal seria apreendido pelo modo Lógico, único lugar onde teria uma existência propriamente real, pois o nosso conceito de ser, o ponto mais alto da abstração, seria capaz de abarcar tudo o que existe, inclusive as realidades além dos sentidos, da Natureza Comum.}

De fato, foi sob a influência de Aristóteles que a Escolástica adotou uma posição Realista moderada, por meio da síntese de São Tomás e dos escritos de Pedro Abelardo, o qual aprofundou as questões propostas por Porfírio, no Isagoge. Tais questões eram: I. Os gêneros e as espécies existem na natureza ou são construções mentais? II. Admitindo que sejam verdadeiros, seriam essências corpóreas ou incorpóreas? III. Caso sejam incorpóreas, existem separadamente dos objetos sensíveis ou fazem parte deles? Abelardo acrescentaria: caso não existissem mais os indivíduos correspondentes, ainda assim haveria os Universais?

Uma grande contribuição ao debate viria, mais tarde, 
com John Duns Scot, de Oxford. Contrário à solução tomista de distinção real entre a essência em si mesma e a essência do que é individual ou produto da mente, o Doutor Sutil cria o termo Natureza Comum para definir algo real e, ao mesmo tempo, comum a certa qualidade de seres. Para Scot, não é preciso que tal Natureza exista num objeto para que seja real, criando, daí, uma distinção formal em relação à individualidade dos seres, que ele nomeia haecceitas. Tal distinção é formal porque a Natureza Comum e a haecceitas seriam "formalitates", ou seja, qualidades diversas somente para a mente, mas inseparáveis como elementos de um mesmo ser.

A haecceitas é um princípio de individuação, pois assim como Sócrates foi um ser humano, no sentido de sua Natureza Comum, foi um homem específico devido à sua haecceitas, ou individualidade especial. Tal distinção é formal, pois Sócrates era um só, mas, para Scot, a mente humana precisa desta separação, para a apreensão racional. Existiria, assim, apenas um tipo de Universal na proposta de Scot, apresentado em potência pela Natureza Comum, e concebido como predicado de vários existentes quando contraído em um individual.

Este Universal está no âmbito do que é chamado por Scot de modo Metafísico, no qual os objetos se assemelham aos da lógica, por sua generalidade, embora tenham a mesma realidade dos objetos físicos. Existiriam, ainda, o modo Físico, dos individuais existentes e o modo Lógico, ou reino da mente. O Universal seria apreendido pelo modo Lógico, único lugar onde teria uma existência propriamente real, pois o nosso conceito de ser, o ponto mais alto da abstração, seria capaz de abarcar tudo o que existe, inclusive as realidades além dos sentidos, da Natureza Comum. A semelhança destes três modos de Scot com as categorias peirceanas não é mera coincidência.

De fato, a questão dos Universais foi analisada por Peirce durante décadas e foi o amadurecimento de seu Realismo, baseado em Scot, que o tornaram um dos principais filósofos das ciências da linguagem. Assim, em 1883, com o artigo - "Lógica dos Relativos", Peirce deixou de lado sua antiga lógica do sujeito e predicado, ao criar a idéia de sistemas relacionais. "Branco", por exemplo, deixou de ser uma classe de coisas e passou a ser uma condição universal, capaz de ser satisfeita por muitos singulares, ou seja, um Universal.

Nesta nova lógica, os sujeitos passaram a denotar objetos singulares, ou seja, índices, que apontam para elementos dinâmicos existentes fora da cognição. Assim, tanto o singular quanto o geral estão na realidade externa à cognição humana, o que evidencia uma postura Realista já bastante clara. Fred Michael descreve esta última fase do realismo de Peirce:

"O real, na última versão de Peirce, é independente da cognição, e assim independente da investigação, o que talvez explique como Peirce podia abandonar a sua caracterização do real como aquilo que a investigação revelaria ao final. E suas categorias não são mais categorias da experiência, como foram para Kant e tinham sido para Peirce até aquela época; as categorias baseadas na nova lógica dos predicados, em contraste com as categorias da lógica de classes inicial, são categorias da realidade externa." (Michael, 1988, p.334)

Este Realismo mais elaborado de Peirce compreende dois tipos de generalidade. Uma relativa ao que não é completamente determinado, ou individual, embora seja como Scot diria contraído em alguma individualidade. A outra é aquela das proposições e leis, que enumeração nenhuma poderia exaurir, pois compreende fenômenos possíveis ou futuros. Este segundo tipo, portanto, conduz o Realismo de Peirce além das concepções de Scot, pois atribui realidade a fenômenos externos à cognição humana, os quais não são individuais.

Ao aperfeiçoar a idéia scotista de distinção formal entre Natureza Comum e haecceitas, Peirce eliminou a necessidade de contração da primeira para a individuação na segunda. A Natureza Comum gerou, assim, dois tipos de generalidade: aquela que não é completamente determinada ou individual foi ligada à Primeiridade e a generalidade das proposições e leis tornou-se Terceiridade. Por sua vez, a haecceitas foi associada à Secundidade, ou seja, a categoria que compreende os fatos brutos da realidade. Daí, nos processos semióticos, a generalidade do que não é completamente determinado ou individual, da esfera da predicação, é associada a um individual, haecceitas, ou sujeito da proposição verbal, através de outra generalidade, ou seja, aquela das leis que regem estas proposições.

\section{Indeterminação e o "esteticamente admirável"}

É exatamente nesta fase final de seu Realismo que Peirce vai enfatizar a generalidade da Primeiridade, ao assumir sua negligência com a estética e, daí, desenvolver o conceito de Summum Bonum como referência para os processos de significação e, portanto, da comunicação humana. Segundo Peirce, a significação está sempre em busca de uma razoabilidade pragmática ou Summum Bonum, que não é apenas lógica, pois se encontra apoiada na ética, a qual, por sua vez, tem como referência última o "esteticamente admirável":

Mas, para apresentar a questão da estética em sua pureza, devemos eliminar dela não apenas todas as considerações acerca de esforço, mas todas as considerações sobre ação e reação, incluindo toda consideração acerca da nossa recepção do prazer, tudo, em síntese, que pertença à oposição entre ego e nãoego. Não temos em nossa língua uma palavra com a generalidade requisitada. O grego kalós, o francês beau apenas se aproximam, sem atingi-la exatamente. "Fine" seria uma pobre substituta. Belo é mau, porque 
um modo de ser kalós depende essencialmente de a qualidade ser não-bela. Talvez, contudo, a frase "o belo do não belo" não fosse ofensivo. Mas "beleza" é muito superficial ainda. A questão da estética é, usando o termo Kalós (do grego, "admirável"): Qual é aquela qualidade que, na sua presença imediata, é Kalós? A ética deve depender desta questão, assim como a lógica depende da ética. A estética, portanto, embora eu a tenha negligenciado terrivelmente, parece ser, possivelmente, a primeira e indispensável propedêutica para a lógica, e a lógica da estética parece ser uma parte distinta da ciência lógica que não deve ser omitida (Peirce, 1931-58, CP 2.199).

Assim, Peirce funda a sua mais elaborada teoria da significação sobre algo que independe de qualquer tipo de consideração por parte de quem quer que seja. Sustentar tal concepção de algo que é admirável por si só, sem que seja possível determinar por qual motivo, só é factível em vista do Realismo Escolástico e seu anti-fundacionismo, que recusa seja o essencialmente necessário ou o absolutamente certo. Daí, a vagueza caracteriza este conceito, que, por pertencer à categoria da Primeiridade, não se encontra sequer na esfera da existência, embora possa ser real. Se não existe, nada pode ser oposto a ele, mesmo idéias de falta, incongruência, ou qualquer outra qualidade negativa, pois oposições são fenômenos da esfera da existência (Peirce, 1931-58, CP. 5.132).

Entretanto, se não há nenhuma necessidade no esteticamente admirável, como é possível que ele deva ser a base para os processos de significação, entre eles a comunicação humana, rumo à razoabilidade e ao Summum Bonum? A saída que Peirce encontrou para estes e outros dilemas gerados pelo fato dos fenômenos da Primeiridade constituírem o fundamento de processos envolvendo as demais categorias, ou seja, a existência e o pensamento, foi se apoiar na idéia de Lume Naturale, a exemplo de Galileu. Para Peirce, deve existir alguma tendência natural que leve a um acordo entre estas idéias que se sugerem à mente e aquelas relacionadas a leis da natureza, ou seja, "é mais do que uma mera figura de linguagem dizer que a natureza fecunda a mente do homem com idéias que, quando se desenvolvem, parecem com seu gerador, a Natureza" (Peirce, 1931-58, CP 1.80-1, 5.591). Em outro ponto de seus Collected Papers, Peirce se refere ao Lume Naturale com as seguintes palavras:

Desta forma, considerações gerais relativas ao universo, considerações estritamente filosóficas, quase demonstram que se o universo se conforma, com algum grau de precisão, a certas leis altamente pervasivas, e se a mente humana tem se desenvolvido sob a influência destas leis, é de se esperar que ela deva ter uma luz natural, ou luz da natureza, ou insights instintivos, ou inclinação tendendo a fazê-la adivinhar estas leis acertadamente. Esta conclusão é confirmada quando descobrimos que todas as espécies animais são dotadas de inclinações similares. (Peirce, 1931-58, CP 5.604)

Contudo, Peirce não está se referindo, aqui, a uma mente individual. Coerente com seu realismo escolástico e com a defesa dos Universais, Peirce deriva seu conceito de ideal estético do pensamento coletivo, fruto de um processo de heterocríticas (Peirce, 1931-58, 1.574). Diz o autor:

Se a conduta é para ser completamente deliberada, o ideal deve ser um hábito de sentimento que cresceu sob a influência de um processo de autocríticas e de heterocríticas; e a teoria da formação deliberada de tais hábitos de sentimento é o que vem a ser chamado de estética (Peirce, 1931-58, CP 1.574).

Esta heterocrítica é o que permitiria ao pensamento coletivo manter sua busca permanente pelo autocontrole dos próprios processos reflexivos, aproximando-o do ideal estético. O desafio seria atingir a consciência dos princípios-guia que organizam os processos de significação, o que propiciaria a geração de novos hábitos mentais, de ação e de sentimento sempre que a realidade externa assim o exigisse, ou seja, o Summum Bonum.

\section{Peirce funda a sua mais elaborada teoria da significação sobre algo que independe de qualquer tipo de consideração por parte de quem quer que seja.}

Neste ponto, podemos retomar a primeira parte deste trabalho, observando que a convergência de ênfases na indeterminação observada no grupo de epistemologia da Compós, no congresso de 2007, talvez possa ser compreendida como uma tomada de consciência coletiva desta esfera do "esteticamente admirável". Estaríamos, então, diante de um fenômeno com qualidades muito vagas, porém percebido como "admirável" por um pensamento coletivo. Segundo os autores, valorizar a indeterminação seria a saída para uma melhor definição do campo, com a maioria deles articulando este pensamento ao atual contexto de mudanças tecnológicas.

Estas associações de qualidades deste tipo à comunicação não poderiam, logicamente, ter sua origem em padrões de pensamento ou mesmo em ações concretas, 
verificáveis, senão deixariam de ser tão incertas. A partir daí, nossa hipótese é de que as qualidades que esta mente coletiva estaria percebendo poderiam estar relacionadas a um mero sentimento de crescente compartilhamento comunicacional, permitido pela atual rede mundial de computadores e sua tecnologia digital. Ou seja, a comunicação imediata, planetária, ubíqua, portátil e em rede poderia estar conduzindo a um sentimento coletivo "admirável", que, no limite, conduziria ao Summum Bonum, do qual os autores citados não só participam como começam a gerar uma autoconsciência dele e a tentar explicitá-la.

Aceitando-se nossa hipótese, esta percepção coletiva de algo "admirável" seria bastante relevante, considerando-se que é sobre tal tipo de fenômeno que ações decisivas e pensamentos críticos encontrariam sua fundação. Ou seja, caso isto, de fato, esteja ocorrendo, estariam sendo criadas condições para processos comunicativos com crescente razoabilidade lógica, considerando-se que hábitos de conduta e de pensamento mais adequados podem ser cultivados sobre hábitos de sentimento considerados admiráveis. Tais hábitos de pensamento já estariam, contudo, na esfera do outro tipo de generalidade proposto por Peirce, chamado de Terceiridade, aquele das proposições, leis e padrões do pensar, entre eles, neste caso, a própria Epistemologia.

\section{A comunicação imediata, planetária, ubíqua, portátil e em rede poderia estar conduzindo a um sentimento coletivo "admirável", que, no limite, conduziria ao Summum Bonum.}

Peirce fundou a idéia de admirável na estética para que este conceito não tenha compromissos com qualquer tipo de pensamento ou ação, e, sim, esteja associado a uma mera qualidade que seja adotada por uma coletividade sem nenhum motivo especial. Considerando-se que a crescente comunicabilidade possa ser algo desse tipo, desejável onde quer que existam possibilidades de trocas de informação nas diversas esferas da natureza, incluindo a humana, talvez seja possível afirmar que o campo esteja, no momento, com sua atenção despertada para tal fenômeno $\square$ FAMEcos

NOTAS

* O presente trabalho foi apresentado ao Grupo de Trabalho "Epistemologia da Comunicação", do XVII
Encontro da Compós, na UNIP, São Paulo, SP, em junho de 2008.

\section{REFERÊNCIAS}

BRAGA, José Luiz. Comunicação: disciplina indiciária. In: Anais do XVI COMPÓS. Curitiba: Tuiuti/ COMPÓS (CD), 2007.

CONTRERA, Malena. Segura em meio ao desencanto: a comunicação fundada no pensamento mecânicofuncional. In: Anais do XVI COMPÓS. Curitiba: Tuiuti/COMPÓS (CD), 2007.

FRANÇA, Vera. Contribuições de G. H. Mead para pensar a comunicação. In: Anais do XVI COMPÓS. Curitiba: Tuiuti/ COMPÓS (CD), 2007.

MACHADO, Irene. Em contexto, fora do contexto: experiências sistêmicas nos estudas da comunicação como mente da cultura. In: Anais do XVI COMPÓS. Curitiba: Tuiuti/ COMPÓS (CD), 2007.

MASELLA, Paulo. Comunicação: entre o espaço visível do meio técnico e o invisível do acontecimento. In: Anais do XVI COMPÓS. Curitiba: Tuiuti/ COMPÓS (CD), 2007.

MICHAEL, Fred. "Two forms of scholastic realism in Peirce's philosophy". In: Transactions of the Charles Sanders Society, Vol. XXIV, $\mathrm{n}^{\circ}$ 3, Amherst: University of Massachusetts Press, 1988.

PIMENTA, Francisco J. Paoliello. Semiótica, como teoria da representação, e o campo da Comunicação. In: Anais do XVI COMPÓS. Curitiba: Tuiuti/ COMPÓS (CD), 2007.

PEIRCE, Charles. Sanders Collected Papers. 8 vols. Cambridge: Harvard University Press, 19311958.

ROSSETTI, Regina. A linguagem como mediação da intuição. In: Anais do XVI COMPÓS. Curitiba: Tuiuti/ COMPÓS (CD), 2007.

SANTOS, Tarcyane Cajueiro. O acontecimento comunicacional. In: Anais do XVI COMPÓS. Curitiba: Tuiuti/ COMPÓS (CD), 2007.

VASSALO DE LOPES, Maria Immacolata. Comunicação, disciplinaridade e pensamento complexo. In: Anais do XVI COMPÓS. Curitiba: Tuiuti/ COMPÓS (CD), 2007. 